\title{
Early predictors of success of non-invasive positive pressure ventilation in hypercapnic respiratory failure
}

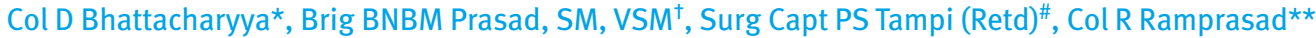

\section{ABSTRACT}

\section{BACKGROUND}

Non-invasive positive pressure ventilation (NIPPV) has emerged as a significant advancement in the management of acute hypercapnic respiratory failure.

\section{METHOD}

Patients with hypercapnic respiratory failure requiring ventilation therapy (respiratory rate $[R R]$ of $>30$ breaths per minutes, $\mathrm{PaCO}_{2}>55 \mathrm{mmHg}$ and arterial $\mathrm{pH}<7.35$ ) were included in the study. Baseline clinical parameters and arterial blood gas (ABG) were recorded before initiating NIPPV. Clinical parameters including heart rate (HR), RR, oxygen saturation and ABG were revaluated at 1,4 , and 24 hours after initiation of NIPPV. Change in these parameters and need for intubation was evaluated.

\section{RESULTS}

Of the 100 patients, 76 (76\%) showed improvement in clinical parameters and $A B G$. There was improvement in $\mathrm{HR}$ and $\mathrm{RR}, \mathrm{pH}$, and $\mathrm{PCO}_{2}$ within the first hour in the success group and these parameters continued to improve even after four and 24 hours of NIPPV treatment. Out of 24 (24\%) patients who failed to respond, 13 (54\%) needed endotracheal intubation within one hour. The failure group had higher baseline HR than the success group.

\section{CONCLUSION}

Improvement in $\mathrm{HR}, \mathrm{RR}, \mathrm{pH}$, and $\mathrm{PCO}_{2}$ one hour after putting the patient on NIPPV predicts success of non-invasive positive pressure ventilation in hypercapnic respiratory failure.

MJAFI 2011;67:315-319

Key Words: acute respiratory failure; chronic obstructive pulmonary disease; non-invasive ventilation

*Senior Advisor (Medicine \& Respiratory Medicine), **Senior Advisor (Anaesthesia \& Critical Care), Military Hospital (CTC), Pune - 40, ${ }^{+}$Commandant, Military Hospital, Wellington, Tamil Nadu, " Consultant (Pulmonologist \& Physician), Bombay Hospital, Mumbai - 20.

Correspondence: Col D Bhattacharyya, Senior Advisor (Medicine \& Respiratory Medicine), Military Hospital (CTC), Pune - 40. E-mail:dbhatta@rediffmail.com

Received: 23.04.2010; Accepted: 19.08.2011

doi: 10.1016/S0377-1237(11)60075-0

\section{INTRODUCTION}

Mechanical ventilation (MV) is a form of life support measure for patients with acute respiratory failure. The primary aim of it is to achieve adequate alveolar ventilation along with improved oxygen exchange by providing mechanical breaths. Mechanical ventilation can be delivered invasively or non-invasively. It is delivered invasively via an endotracheal or tracheostomy tube. In contrast, non-invasive ventilation (NIV) is delivered through an alternative interface without any intratracheal intervention. Moreover, MV is associated with a host of attendant complications, like ventilator-associated pneumonia, barotraumas, inability to speak, swallow or eat, and laryngeal trauma while the tube is in place or after its removal. ${ }^{1,2}$

During the last two decades, non-invasive modalities have been developed and have also been popularised to augment alveolar ventilation and oxygenation without the need for an artificial airway. Various recent studies have demonstrated their effectiveness in management of respiratory failure. Non-invasive positive pressure ventilation (NIPPV) using face mask or nasal mask is one such modality. It works by providing pressure support that gives ventilatory assistance during inspiration, allows respiratory muscles to work less, increases the volume inspired per minute and improves arterial blood gas (ABG) levels. Its use has become more common as its benefits are increasingly recognised. However, the frequency of NIPPV in patients with acute respiratory failure varies amongst studies. ${ }^{3,4}$

In some patients, with acute hypercapnic respiratory failure, NIV is inadequate and invasive ventilation is required for management of respiratory failure. The failure rates in such patients range from $24 \%$ to $50 \%$ in different studies. Failure of initial trial of NIPPV can lead to a delay in endotracheal intubation thus causing an increase in morbidity and mortality. ${ }^{6}$

Thus, determination of early predictors of success of NIPPV is important to identify the patients who are likely to benefit from NIPPV. Patients responding to NIPPV will be continued with NIPPV. Rest of the patients will be intubated and put on invasive ventilator early. This will reduce the incidence of higher mortality and morbidity associated with undue delay in putting the patients on invasive MV. ${ }^{4,5}$ In view of paucity of such data from the Armed Forces hospitals, a prospective study was carried out to identify the early predictors of success of NIPPV in hypercapnic respiratory failure. 


\section{MATERIALS AND METHOD}

This was a prospective study carried out at a tertiary care service hospital between 1 July 2007 and 30 June 2009. A total of 100 consecutive patients presenting with hypercapnic respiratory failure were included in the present study as per the following inclusion criteria ${ }^{6,7}$ :

1. Difficulty in breathing spontaneously as expressed by the patients.

2. Respiratory rate (RR) of $>30$ breaths per min or $<12 /$ minute.

3. Sign of increased work of breathing or paradoxical respiration.

4. Partial pressure of carbon dioxide $\left(\mathrm{PCO}_{2}\right)>55 \mathrm{mmHg}$.

5. Arterial $\mathrm{pH}<7.35$.

Exclusion criteria for the patients for this study were $\mathrm{w}^{6,7}$ :

1. Unco-operative patients.

2. Haemodynamic and cardiac instability (unstable angina, acute myocardial infarction).

3. Serious cardiac arrhythmias.

4. Unconscious patients.

5. Need for endotracheal intubation on admission to protect the airways or to manage respiratory secretions.

6. Inability to properly fit the facemask due to skeletal deformity.

Hospital ethical committee clearance was obtained before the study was started. Informed consent was taken from all patients included in the study. All patients were managed in the intensive care unit. A portable non-invasive ventilator (BiPAP, Respironics) was used in the spontaneous mode, using full face mask (Respironics). The inspiratory pressure support was initially set at $10 \mathrm{~cm}$ of water. Expiratory pressure was set at $6 \mathrm{~cm}$ of water. The pressure was gradually increased to reach the optimum level for each patient.

Oxygen was administered through the full facemask until oxygen saturation $\left(\mathrm{SpO}_{2}\right)$ was $>90 \%$. The patients electrocardiogram (ECG), $\mathrm{SpO}_{2}$, blood pressure (BP), and RR were continuously monitored. Standard medical treatment including inhalational bronchodilators, intravenous corticosteroids, xanthenes and whenever appropriate, antibiotics, diuretics, or vasopressors were given in addition to NIPPV.

Clinical history was obtained from the patients or from family members at the time of admission. A thorough clinical examination was carried out. Patients' RR, blood pressure, oxygen saturation $\left(\mathrm{SpO}_{2}\right)$, and ECG were continuously monitored. Arterial blood gas analysis was done before the patient was put on NIPPV, and after 1, 4 and 24 hours.

Functional limits caused by chronic pulmonary disease were evaluated using a correlated home "activities of daily living" (ADL) score. ${ }^{4}$ This scoring was as follows: $1=$ severe limits (patient short of breath at rest and does not perform any ADL); $2=$ moderate limits (patient short of breath with light activities and unable to perform two or more ADL); and $3=$ no limits (no more than one limitation in ADL).

The mask was examined for leak, skin abrasion, and patient satisfaction. If satisfactory degree of patient comfort, ventilation and oxygenation was not achieved, ABG was repeated. Patients were put on invasive MV when there was any deterioration.

Treatment with NIPPV was considered successful if there was expression of improvement of breathlessness by the patient, RR improved to $<30 /$ minute, there was improvement of signs of increased work of breathing, tachycardia improved (heart rate $(\mathrm{HR})<100 /$ minute), $\mathrm{pH}$ became $>7.35$ with a fall in $\mathrm{PCO}_{2}$ from base line, thereby avoiding intubation in these patients.

Pre-NIPPV measurements were compared with the measurements obtained at 1, 4 and 24 hours after NIPPV initiation by generalised linear model (repeated measurement). Data with $P$ values $<0.05$ were considered statistically significant. A logistic regression mode was created using all variables at baseline showing statistically significant association $(P<0.05)$ with the outcome. Dummy variables were created using means as cut-off expect in case of age where median was used.

\section{RESULTS}

A total of 100 patients presenting with hypercapnic respiratory failure were included in the present study. Age of the study population was 41-83 (with mean age 59.4) years and out of them 88 were males and 12 were females.

Distribution of patients as per aetiology of hypercapnic respiratory failure is provided in Table 1 .

Seventy-six $(76.0 \%)$ patients showed improvement with NIPPV and $24(24.0 \%)$ patients failed the initial trial of NIPPV requiring intubation. Summary of results of the other study variables at baseline, at one hour, at four hours and at 24 hours time periods are shown in Table 2 .

Multiple logistic regression analysis of study variables at base line like $\mathrm{ADL}$ score, $\mathrm{HR}, \mathrm{RR}, \mathrm{PCO}_{2}$, and $\mathrm{pH}$ was done. Activities of daily living score and $\mathrm{PCO}_{2}$ were found to be statistically significant (Table 3).

Base line activities of ADL was found to be low $(2.28 \pm 0.38$ vs $1.16 \pm 0.35)$ in failure group as compared to the patients in the success group (Table 4). Base line HR (135 \pm 9.3 vs $106 \pm 12.4)$ and RR (37.8 \pm 3.9 vs $33.6 \pm 2.52)$ were also higher in the failure group compared to the group with successful patients (Table 4). Initial pH was lower in failure group (7.2 \pm 0.04 vs $7.32 \pm 0.06)$. $\mathrm{PCO}_{2}$ was also high in the failure group. There was no significant

Table 1 Distribution of patients as per aetiology of hypercapnic respiratory failure $(n=100)$.

Disease $n$ (\%)

COPD with acute exacerbation $86(86)$

Asthma with acute exacerbation

Obstructive sleep apnoea

Polytrauma

COPD: chronic obstructive pulmonary disease. 
Table 2 Summary of results of study variables at baseline, at 1-, 4- and 24-hours time period.

S. no.

\section{Variable name}

HR

$\mathrm{RR}$

$\mathrm{PCO}_{2}$

$\mathrm{PO}_{2}$

$\mathrm{pH}$

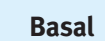

$115.7 \pm 12.07$

$34.5 \pm 2.76$

$82.79 \pm 12.68$

$54.7 \pm 8.13$

$7.29 \pm 0.023$

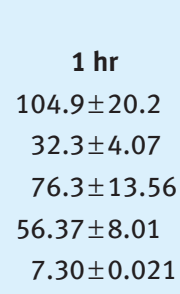

Mean \pm SD

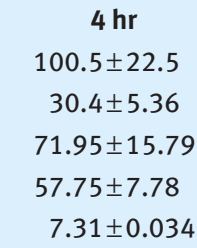

$24 \mathrm{hr}$

$97.9 \pm 25.3$

$28.36 \pm 6.65$

$67.59 \pm 18.84$

$59.1 \pm 7.84$

$7.31 \pm 0.047$
$P$ *

0.000

0.000

0.000

0.000

0.000

HR: heart rate, RR: respiratory rate.

No. of follow-up measurements $=3$, baseline measurement $=1$.

Statistical analysis: generalised linear model (repeated measurement).

*Statistically significant.

Table 3 Multiple logistic regression models of study variables at baseline level and odds ratio.

$\begin{array}{lcc}\begin{array}{l}\text { Variables } \\ \mathrm{HR}\end{array} & \mathrm{OR}(95 \% \mathrm{Cl}) & \boldsymbol{P} \\ & 1 & 0.052 \\ \mathrm{RR} & 0.215(0.046-1.016) & \\ & 1 & 0.276 \\ \mathrm{PCO}_{2} & 2.15(0.54-8.56) & 0.015^{*} \\ \mathrm{pH} & 1 & 0.126 \\ & 12.41(1.64-93.68) & \\ \mathrm{ADL} & 1 & 0.000^{*}\end{array}$

HR: heart rate, RR: respiratory rate, ADL: activities of daily living. Statistical analysis: multiple logistic regression model $\left(R^{2}=0.408\right)$. *Statistically significant.

difference found in age, haemoglobin, and biochemical parameters at the time of admission.

After one hour of NIPPV trial $\mathrm{pH}, \mathrm{HR}$, and RR improved in success group as compared to failure group (7.36 \pm 0.04 vs $7.28 \pm 0.04,92 \pm 14.8$ vs $136 \pm 8.04,27.8 \pm 5.87$ vs $37.2 \pm 3.95)$, respectively. Improvement was maintained after four and 24 hours of therapy. There was also improvement in $\mathrm{PCO}_{2}$ after one hour in success group (61.2 \pm 9.31 vs $80.2 \pm 19.22)$, which was maintained after four $(62.4 \pm 9.67$ vs $81.3 \pm 19.7)$ and 24 (56.6 \pm 8.54 vs $82.4 \pm 19.58$ ) hours of therapy.

Of the patients in success group, co-morbid conditions were present in $15(19.7 \%)$ cases, while of the 24 patients in failure group, 14 (58.3\%) patients had associated co-morbidity (Table 5).

\section{DISCUSSION}

Non-invasive positive pressure ventilation should be used early in the course of COPD exacerbations with hypercapnic acute respiratory failure. Selection of appropriate patient is the key to the successful application of NIPPV. The selection process takes into account a number of factors, including the patient's clinical characteristics and risk of failure on NIPPV. Ultimately, it becomes a clinical judgement depending largely on physician experience. Predictors of success of NIPPV ${ }^{8}$ include a better neurological status (and hence more co-operativeness), ability to protect the airway, and no more than moderate acid-base or gas exchange derangement. Several studies have also found that improvements in $\mathrm{pH}$, arterial $\mathrm{PCO}_{2}$, and level of consciousness within the first hour or two of NIPPV initiation are strong predictors of success. ${ }^{8}$ If NIPPV does not improve $\mathrm{pH}$ and RR within the first hour or two, intubation should be considered. Patients with high APACHE II scores, inability to minimise the amount of mouth leak (because of lack of teeth, secretions, or breathing pattern) or inability to co-ordinate with NIPPV are unlikely to improve with NIPPV and there should be a low threshold for intubation and MV. Patients who fail on NIPPV have a significantly higher incidence of pneumonia, are underweight, have greater level of neurological deterioration, and reduced compliance with ventilation, compared with those who are successfully treated. Patients failing on NIPPV have a significantly greater abnormality in $\mathrm{PaCO}_{2}$ and $\mathrm{pH}$ before starting NIPPV. Baseline $\mathrm{pH}$ is found to be able to predict success or failure of NIPPV (mean pH of 7.28 in success group vs 7.22 in failure group) with a sensitivity of $97 \%$ and specificity of $71 \% .{ }^{9}$ However, Poponick et $\mathrm{al}^{10}$ found no relationship between baseline parameters and the likelihood of success of NIPPV with the lack of change in blood gases after one hour trial being the best predictor for the need for ETI.

Early initiation of NIPPV is recommended so patients have time to adapt and respiratory crises can be averted. On the other hand, NIPPV begun too early might be unhelpful and wasteful of resources if treated patients would have done well without any ventilatory assistance. For this reason, selection guidelines suggest first establishing the need for ventilatory assistance according to clinical and blood gas criteria and exclusion of patients in whom NIPPV is contraindicated or likely to fail. ${ }^{11}$ Coma or confusion, upper gastrointestinal bleeding, high risk of aspiration, haemodynamic instability or uncontrolled arrhythmia have been suggested as contraindications to NIPPV. 
Table 4 Summary of results of study variable according to group (success and failure) at baseline, at 1-, 4- and 24-hours time period.*

S. no. Variable

\begin{tabular}{|c|c|c|c|c|c|}
\hline & \multicolumn{3}{|c|}{ Mean \pm SD } \\
\hline & & Basal & $1 \mathrm{hr}$ & $4 \mathrm{hr}$ & $24 \mathrm{hr}$ \\
\hline 1 & HR & $106 \pm 12.4$ & $92 \pm 14.8$ & $90.3 \pm 12.4$ & $83.2 \pm 1$ \\
\hline 2 & $\mathrm{RR}$ & $33.6 \pm 2.52$ & $27.8 \pm 5.8$ & $25.7 \pm 5.8$ & $22.6 \pm 4$ \\
\hline 3 & $\mathrm{PO}_{2}$ & $86.1 \pm 19.5$ & $90.1 \pm 19.8$ & $92.8 \pm 15.3$ & $93.4 \pm 1$ \\
\hline 4 & $\mathrm{PCO}_{2}$ & $71.2 \pm 10.8$ & $61.2 \pm 9.3$ & $62.4 \pm 9.6$ & $56.6 \pm 8$ \\
\hline 5 & $\mathrm{Ph}$ & $7.32 \pm 0.06$ & $7.36 \pm 0.04$ & $7.37 \pm 0.04$ & $7.38 \pm 0$ \\
\hline 6 & $\mathrm{ADL}^{\#}$ & $2.28 \pm 0.3$ & & & \\
\hline \multicolumn{6}{|c|}{$\begin{array}{l}\text { HR: heart rate, RR: respiratory rate, ADL: activities of daily living. } \\
\text { No. of follow up measurements }=3 \text {, baseline measurement }=1 \text {. } \\
{ }^{*} \text { Statistical analysis - Generalised Linear Model (repeated measurement). } \\
{ }^{+} P<0.05-\text { statistically significant. } \\
{ }^{A} \text { ADL score statistically significant difference between success and failure group ( }\end{array}$} \\
\hline \multicolumn{6}{|c|}{ Table 5 Co-morbid conditions of patients $(n=100)$. } \\
\hline \multirow{2}{*}{\multicolumn{3}{|c|}{ Variables }} & Success group & \multirow{2}{*}{\multicolumn{2}{|c|}{$\begin{array}{l}\text { Failure group } \\
\qquad(n=24)\end{array}$}} \\
\hline & & & $(n=76)$ & & \\
\hline \multicolumn{3}{|c|}{ Diabetes mellitus } & 6 & \multicolumn{2}{|r|}{6} \\
\hline \multicolumn{3}{|c|}{ Coronary artery disease } & 5 & \multicolumn{2}{|r|}{6} \\
\hline \multicolumn{3}{|c|}{ Hypertension } & 4 & \multicolumn{2}{|r|}{2} \\
\hline \multicolumn{3}{|c|}{ Total } & 15 & \multicolumn{2}{|c|}{14} \\
\hline
\end{tabular}

In the present study, NIPPV was observed to be successful in rapid and sustained improvement in gas exchange in $76 \%$ patients with acute hypercapnic respiratory failure and the endotracheal intubation could be avoided. The overall efficacy of NIPPV in avoiding intubation in this study is marginally more than the rate reported in published randomised studies. ${ }^{4,12}$ Strictly following the protocol of the study, a highly trained and motivated team of respiratory technicians along with respiratory physicians, intensivist, resident doctors, and ICU trained nurses may probably have helped to achieve the high success rate with the NIPPV. It is shown in this study that with persistence, adjustment of settings, and with change of interface in cases where indicated the overall success rate of NIPPV can be improved.

The clinical variables showing association (odds ratio) with NIPPV outcomes were ADL score and $\mathrm{PCO}_{2}$ with higher $\mathrm{PCO}_{2}$ and higher ADL scores predicting favourable outcome. In our study, failure group had significantly higher HR and RR at the time of enrollment. Changes in HR and RR after one hour of ventilation were also found to predict the outcome in our study. We found that patient with improvement in tachycardia and tachypnoea soon after starting of NIPPV responded successfully to it.

In the ABG parameters, acidosis is an indicator of severity of decompensations in acute hypercapnic respiratory failure and has been shown to predict death in number of studies of acute exacerbation of COPD. ${ }^{4,5}$ In a retrospective study aimed at identifying patient with COPD who could be treated successfully with NIPPV, Ambrosino et $\mathrm{al}^{9}$ found that patients in whom
NIPPV treatment failed were significantly more acidotic at baseline than those successfully treated. In our study, the initial $\mathrm{pH}$ of failure group was lower and did not improve after one hour of NIPPV initiation.

In a recently published retrospective study on 119 consecutive patients presenting with acute type II respiratory failure and meeting criteria for NIV use, Salahuddin et $\mathrm{al}^{13}$ observed that overall survival rate was $76.5 \%$, and intubation rate was $12.6 \%$. Statistically significant improvements were observed in the $\mathrm{pH}$ and $\mathrm{PCO}_{2}$ at 24 hours and 48 hours compared to baseline $(7.28$ vs $7.37, P<0.001 ; 74.2$ vs $65, P<0.001)$. A serum $\mathrm{HCO}_{3}>35 \mathrm{mEq} / \mathrm{L}$ (adjusted odds ratio 0.9; $95 \% \mathrm{CI} 0.83,0.98$, $P<0.015)$ was found to have identified those patients who were less at risk for intubation.

Most of the studies have considered the patients of acute hypercapnic respiratory failure affected by a single pulmonary pathology and have not taken account of the other medical conditions. Seneff et $\mathrm{al}^{14}$ showed that the presence of other comorbidity in patients with hypercapnic respiratory failure might be associated with worse prognosis. Similarly, in the above quoted study by Salahuddin et $\mathrm{al}^{13}$ on multivariate regression analysis, sepsis at admission was found to have increased mortality (adjusted odds ratio 26.4; 95\% CI 2.3, 304, $P<0.009$ ).

Limitations of functional daily life activity as assessed by daily ADL scale was found to be associated with failure. In our study, as in study by Moretti et $\mathrm{al}^{15} 24$ patients who required intubation had significant higher rate of other co-morbidity (58.3\% vs $19.7 \%, P<0.05$ ) at the time of admission.

The usefulness of the present study lies in the fact that it shows that improvement of $\mathrm{HR}, \mathrm{RR}, \mathrm{pH}$, and $\mathrm{PCO}_{2}$ one hour after the patient has been put on NIPPV is very likely to be maintained at four and 24 hours. Hence these patients improved over a period of a few days and were discharged from the hospital, being put on appropriate medical treatment. On the contrary, patients showing deterioration in $\mathrm{HR}, \mathrm{RR}, \mathrm{pH}$, and $\mathrm{PCO}_{2}$ after one and four hours required to be kept under very close observation. They are very likely to require intubation in case of any further deterioration. 
It is recommended that the physicians including resident doctors and nurses on duty managing patients of hypercapnic respiratory failure on NIPPV should be observant about the changes in the patients $\mathrm{HR}, \mathrm{RR}, \mathrm{pH}$, and $\mathrm{PCO}_{2}$ at one hour and subsequently, so that patients requiring invasive ventilation may be intubated at the earliest to prevent avoidable increase in morbidity and mortality.

Intellectual Contributions of Authors

Study concept: Col D Bhattacharyya, Brig BNBM Prasad, SM, VSM, Surg Capt PS Tampi (Retd), Col R Ramprasad

Drafting and manuscript revision: Col D Bhattacharyya, Col R Ramprasad

Statistical analysis: Col D Bhattacharyya

Study supervision: Col D Bhattacharyya, Col R Ramprasad

\section{CONFLICTS OF INTEREST}

This study has been financed by the research grants from the office of the DGAFMS.

\section{REFERENCES}

1. Nava S, Hill N. Non-invasive ventilation in acute respiratory failure. Lancet 2009;374:250-259.

2. Hill NS, Brennan J, Garpestad E, Nava S. Noninvasive ventilation in acute respiratory failure. Crit Care Med 2007;35:2402-2407.

3. Sharma RM, Handa A, Chaturvedi R. Invasive to noninvasive ventilation in chronic obstructive pulmonary disease. MJAFI 2003;59:264-265.

4. Singh VK, Khanna P, Rao BK, Sharma SC, Gupta R. Outcome prediction for non-invasive positive pressure ventilation in acute respiratory failure. JAPI 2006;54:361-365.
5. Lightower JV, Eliott MW. Predicting the outcome from NIV for acute exacerbation of COPD. Thorax 2000;35:815-816.

6. Karmer N, Mayer TJ, Meharg J. Randomised prospective trial of noninvasive positive pressure ventilation in acute respiratory failure. Am J Respair Crit Care Med 1995;151:1799-1806.

7. Brochard L, Mancebo J, Wysocki M, et al. Noninvasive ventilation for acute exacerbations of chronic obstructive pulmonary disease. N Eng J Med 1995;333:817-822.

8. Anton A, Guell R, Gomez J, et al. Predicting the result of noninvasive ventilation in severe acute exacerbations of patients with chronic airflow limitation. Chest 2000;117:828-833.

9. Ambrosino N, Foglio K, Rubini F, Clini E, Nava S, Vitacca M. Noninvasive mechanical ventilation in acute respiratory failure due to chronic obstructive airway disease: correlates of success. Thorax 1995;50:755-757.

10. Poponick JM, Renston JP, Bennet RP, Emermann CL. Use of a ventilatory system (BiPAP) for acute respiratory failure in the emergency department. Chest 1999;116:166-171.

11. Liesching $T$, Kwok H, Hill NS. Acute applications of noninvasive positive pressure ventilation. Chest 2003;124:699-713.

12. Martin TJ, Hovis JD, Costantino JP, et al. A randomized prospective evaluation of noninvasive ventilation for acute respiratory failure. Am J Respir Crit Care Med 2000;161:807-813.

13. Salahuddin N, Irfan $M$, Khan $S$, et al. Variables predictive of outcome in patients with acute hypercapnic respiratory failure treated with noninvasive ventilation. J Pak Med Assoc 2010;60: 13-17.

14. Seneff MG, Wagner DP, Wagner RP, Zimmerman JE, Knaus WA. Hospital and 1-year survival of patients admitted to intensive care units with acute exacerbation of chronic obstructive pulmonary disease. JAMA 1995;274:1852-1857.

15. Moretti M, Cilione C, Tampieri A, Fracchia C, Marchioni A, Nava S. Incidence and causes of non-invasive mechanical ventilation failure after initial success. Thorax 2000;55:819-825. 